\title{
Morphological fruit characters and nutritional food value of different jackfruit (Artocarpus heterophyllus Lam.) cultivars in Rajshahi region of Bangladesh
}

\author{
M. Ibrahim ${ }^{1 *}$, M. S. Islam ${ }^{2}$, M. O. H. Helali ${ }^{1}$, A. K. M. S. Alam ${ }^{3}$ and M. Z. Shafique ${ }^{4}$ \\ ${ }^{1}$ Fruits and Food Processing \& Preservation Research Division, BCSIR Laboratories, Rajshahi-6206, \\ Bangladesh. \\ ${ }^{2}$ Regional Horticultural Research Station, Chapai Nawabgonj, \\ ${ }^{3}$ Applied Botany Research Division, and \\ ${ }^{4}$ Drug and Toxin Research Division, Laboratories, Rajshahi-6206, Bangladesh.
}

\begin{abstract}
Morphological fruit characters and nutritional food value of different jackfruit cultivars were studied during May to July 2012 to find out the superior ones in terms of the standard variables. The different cultivars of jackfruit were collected from Rajshahi, Natore, Noagoan and Chapai Nawabgonj. These cultivars showed variability in morphological fruit characters and nutritional food values. Among them the percentage of pulp (38.60-47.37\%), percentage of rind (15.67-20.00\%), percentage of skin (14.86-23.68\%), percentage of seed (09.46-19.33\%), moisture content (63.39-76.62\%), TSS (18.80-27.37\%), total sugar (11.84-17.01\%), vitamin C content (17.82-31.55 mg/100gm) and acidity $(0.037-0.075 \%$ as citric acid) were estimated. The findings show that, evaluation of these promising cultivars have identified them as superior ones. The data provide important information in improving the quality characteristics of jackfruit for plantation and processing industry.
\end{abstract}

Keywords: Morphological fruit characters; Nutritional value; Jackfruit cultivar and Recognition

\section{Introduction}

Jackfruit is well known and the most important fruit of Bangladesh and also it is the "national fruit of Bangladesh". Jackfruit is certainly one of the delicious and esteemed fruits of the world. It is a nutritious fruit and an excellent source of essential minerals, beta carotene (Provitamin A), vitamin C, carbohydrate and energy in human nutrition, therefore, is useful to prevent many deficiency diseases (Salunkhe and Kadam, 1995).

It is widely cultivated in most tropical countries like Bangladesh, India, Burma, Brazil, Philippines, Pakistan, Thailand, Malaysia, Sri Lanka, Africa and some other parts of Australia and America. With increasing recognition of their nutritional value in human diet, these fruits are gaining commercial importance (Salunkhe and Desai, 1984). The jackfruit is hardly regarded as commercial fruit crop although extensively cultivated (Bose and Mitra, 1990).

Jackfruit is a seasonal fruit and a tropical evergreen tree having the botanical name Artocarpus heterophyllas Lam. under genus Artocarpus and family Moraceae (Alam et al., 2011). It is cross pollinated and largely propagated by seeds. Jackfruits are oval or oblong, pale green to yellow-brown in color, rind formed by a number of conical homy protuberances. Raw (tender) jackfruit can be separated into edible (47\%) and non edible portions (53\%) whereas ripe fruit can be separated in five parts, viz.(i) pulp (bulbs), (ii) seeds, (iii) rind, (iv) central core and (v) sheath around the pericarp. Of these parts of jackfruit, pulp is the part most utilized for human consumption. The pulp whether ripe or immature can be used for making jams, jellies, beverages, candies and dehydrated products (Sonwalkar, 1951; Bhatia et al., 1995; Chadha and Pareek, 1993 ). Virtually all parts of the fruit are usable either as food for human consumption or as cattle feed.

Awareness in respect of improved jackfruit production is lacking. In view of the above aspect, the present study has been undertaken to throw light on some of the constituents of jackfruit with a view to apprehending the fruit as a supplementary food having a good nutrient value as well as to select the varieties for plantation with a hope to be a member of jackfruit exporting countries. 


\section{Materials and methods}

The present experiment was carried out at BCSIR Laboratories, Rajshahi during the period from May to July 2012. The freshly harvested jackfruits (10 cultivars) used in this experiment were procured randomly from three Jackfruit garden of Rajshahi, Natore, Noagoan and Chapai Nawabgonj. The jackfruits under experiment were designated as AH001, AH002, AH003, AH004, AH005, AH006, AH007, AH008, AH009 and AH010. The morphological fruit characteristics of the jackfruits viz. the colour, shape, surface and the pulp (bulb) colour, flavour and taste were estimated and presented in Table I. \& Fig. 1. different parameters was compared by least significant difference (LSD) test.

The organoleptic tests and the morphological characters (e.g. colour, flavour and taste) of these ripe jackfruits were carried out and evaluated by a panel of seven judges. The jackfruits were classified as follows on the basis of their grading as excellent $80 \%$ or above, good $70-79 \%$ and fair bellow $70 \%$. The results are presented in Table IV.

\section{Results and Discussion}

The findings of fruit morphological study (Table I, Fig.1.) show that, the fruit colour was found yellowish in the culti

TableI: Morphlogical fruit characters of ten jackfruit cultivars in Rajshahi region

\begin{tabular}{llllllll}
\hline Sl.No. & Accessions & Fruit colour & Fruit shape & Fruit surface & Pulp colour & Pulp taste & Pulp flavour \\
\hline 01. & AH001 & yellowish & Ellipsoid & Spiny & Yellow & Sweet & Weak \\
02. & AH002 & Light yellow & Ellipsoid & Spiny & Yellow & Light Sweet & Stroge \\
03. & AH003 & Yellowish & Oblong & Spiny & Light yellow & Sweet & Stroge \\
04. & AH004 & Redish yellow & Oblong & Spiny & Deep yellow & Deep weet & Stroge \\
05. & AH005 & Light yellow & Oblong & Spiny & Yellowish & Sweet & Weak \\
06. & AH006 & Yellowish & Spherid & Spiny & Light yellow & Light Sweet & Stroge \\
07. & AH007 & Yellowish & Oblong & Spiny & Yellow & Sweet & Medium \\
08. & AH008 & Light yellow & Ellipsoid & Spiny & Yellowish & Sweet & Stroge \\
09. & AH009 & Green yellow & Ellipsoid & Spiny & Yellow & Light Sweet & Stroge \\
10. & AH010 & Yellowish & Oblong & Spiny & Yellow & Sweet & Medium \\
\hline
\end{tabular}

The ripen jackfruits were cleaned, weighed, peeled and the stone (seed) were separated. The weight of whole jackfruit, weight of stone (seed), weight of skin (peel), weight of pulp, were determined using standard methods and the data were presented in Table II.

The total soluble solids (TSS) was determined with a hand refractometer (Alam et al, 2011), sugar was determined by colorimetric method i.e. Anthrone method (Dubois et.al. 1956), vitamin $C$ was determined titrimetrically using 2,6dichlorophenolindophenol (Gryorgy and Pearson,1967), acidity was determined titrimetrically with the visual acidbase titration method (Ranganna, 1986). The $\mathrm{pH}$ was determined with a digital $\mathrm{pH}$ meter (Jayaraman, 1981), moisture was determined by oven drying method (Karmas, 1990) and ash was determined by muffle furnace by ashing method (Modevan and Sridhar, 1982). All experiments were conducted at ambient temperature and carried out in three replications and also the mean values are recorded in Table III. The above data were statistically analyzed and the mean of var of AH001, AH003, AH006, AH007 and AH010 while AH005 and AH008 showed light yellow colour. The cultivars AH001, AH002, AH008 and AH009 produced fruits of ellipsoid shape whereas the cultivars AH003, AH004, AH005, AH007 and AH010 produced oblong shapes of fruits. The surface of the fruits of all the cultivars are spiny. Only the cultivar AH004 obtained deep yellow pulp colour whereas AH001, AH002, AH007, AH009 and AH010 produced yellow pulp colour and pulp of major cultivars were tasted sweet except AH002, AH006 and AH009 which had light sweet taste and AH004 had deep sweet taste.

The strong pulp flavor was observed in most of the cultivars but AH001 and AH005 possessed weak pulp flavor while AH007 and AH010 were of medium type. The findings are in conformity with those of Alam et.al., (2011) (Jagadeesh et al., (2007) and Biswas et al., (2001).

Significant variation was observed among the different cultivars in respect of whole fruit weight. The maximum fruit 

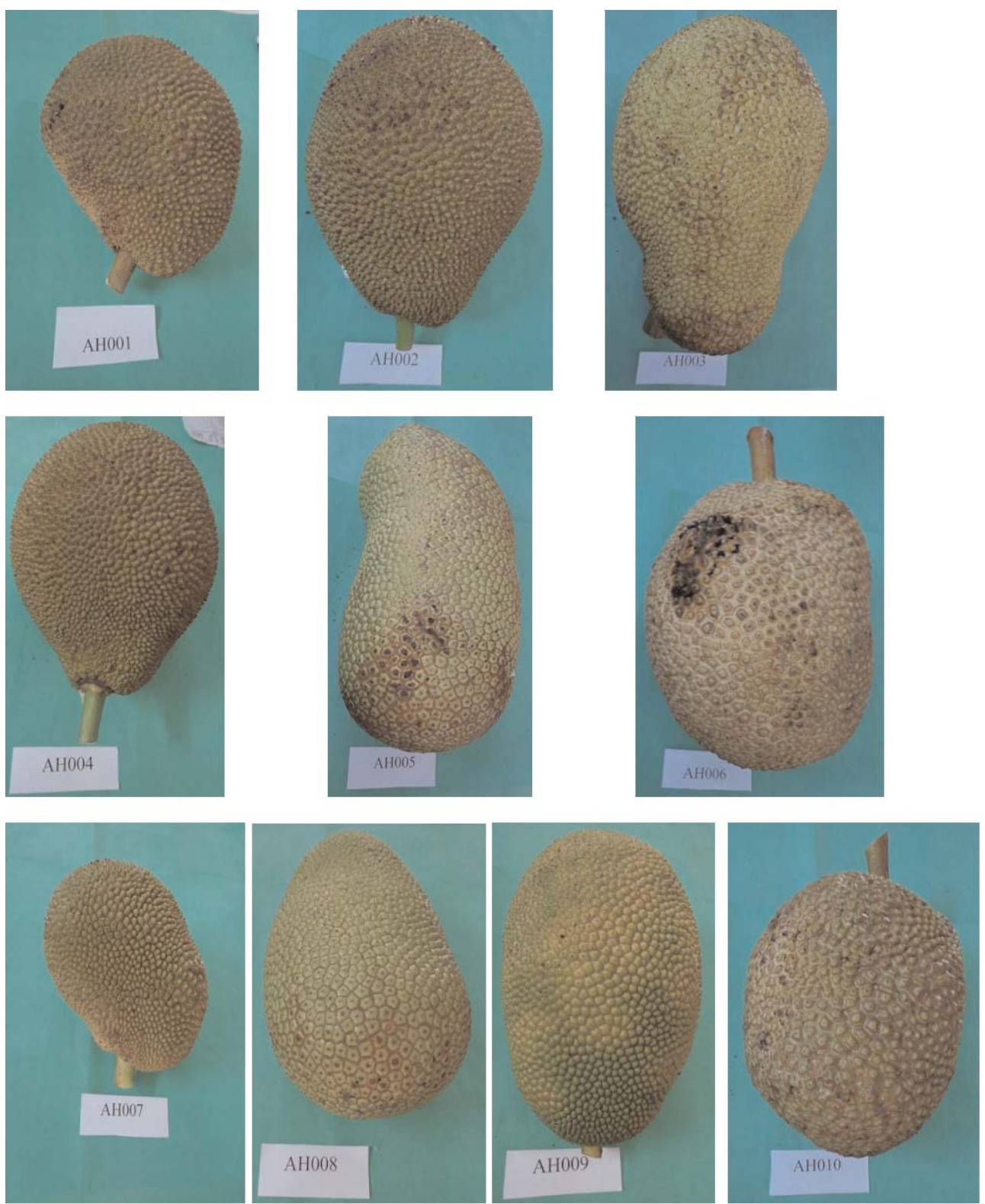

Fig. 1. Ten cultivars of jackfruit in Rajshahi region of Bangladesh

weight was recorded in AH003 (5.70 kg) which was 1.5 times heavier than the next heaviest AH006 $(3.80 \mathrm{~kg})$. The smallest fruit (1.39 kg) was recorded in AH007 (Table II.). The information were similar with the findings of Alam et.al., (2011) who reported jackfruits to be in the range of 2.2 to $5.9 \mathrm{~kg}$ in fruit weight. Fruit is composed percentage of peel (skin), pulp, rind and the composition of fruits are varied among the cultivars (Table II.). Pulp percentages (edible portion) were above $44.44 \%$ of AH002, AH004 and AH006.

The rind percentage ranged from 15.67 to $22.73 \%$, the peel percentage varied from 14.86 to $23.68 \%$. The wastage per- centage varied from 38.33 to $46.04 \%$. The highest wastage cultivars were AH002, AH003 and AH007. The least seeded cultivars were AH004, AH005 and AH006 and maximum were AH009 and AH010, variation in percentage of edible portion (pulp), peel (skin), rind, wastage and seed was also recorded by Alam et al., (2011).

The moisture content, dry mater, TSS , $\mathrm{pH}$, total sugar content, reducing sugar, non reducing sugar, vitamin $\mathrm{C}$ content, acidity and ash content of jackfruit cultivars varied among the cultivars and presented in Table III. and wide variation 
Table II. Morphological fruit characters of ten jackfruit cultivars in Rajshahi region

\begin{tabular}{lccccccc}
\hline SL No & Accessions & $\begin{array}{c}\text { Whole weight } \\
\text { of fruit( kg) }\end{array}$ & $\begin{array}{c}\text { Weight of } \\
\text { Pulp. (\%) }\end{array}$ & $\begin{array}{c}\text { Weight of } \\
\text { Rind (\%) }\end{array}$ & $\begin{array}{c}\text { Weight of } \\
\text { Seed (\%) }\end{array}$ & $\begin{array}{c}\text { Weight of } \\
\text { skin (\%) }\end{array}$ & $\begin{array}{c}\text { Weight of } \\
\text { wastage (\%) }\end{array}$ \\
\hline 1 & 2 & 3 & 4 & 5 & 6 & 7 & 8 \\
\hline 01 & AH001 & 3.50 & 43.45 & 20.00 & 15.71 & 22.86 & 42.85 \\
02 & AH002 & 3.70 & 45.95 & 22.73 & 16.46 & 14.86 & 44.59 \\
03 & AH003 & 5.70 & 38.60 & 21.05 & 16.67 & 23.68 & 44.73 \\
04 & AH004 & 3.60 & 44.44 & 19.44 & 13.89 & 22.22 & 41.67 \\
05 & AH005 & 4.25 & 43.36 & 21.00 & 12.12 & 23.53 & 39.41 \\
06 & AH006 & 3.80 & 45.37 & 17.11 & 13.16 & 22.36 & 43.53 \\
07 & AH007 & 1.39 & 43.17 & 15.67 & 17.98 & 23.18 & 46.40 \\
08 & AH008 & 2.95 & 38.90 & 19.95 & 18.61 & 22.54 & 42.71 \\
09 & AH009 & 3.6 & 38.90 & 21.06 & 19.22 & 18.06 & 38.33 \\
10 & AH010 & 3.75 & 39.33 & 19.14 & 19.33 & 22.20 & 40.50 \\
\hline & LSD 5\% & 0.0506 & 0.0095 & 0.0094 & 0.7280 & 0.0338 & 0.0338 \\
& LSD 1\% & 0.0693 & 0.0129 & 0.0129 & 0.0995 & 0.0463 & 0.0463 \\
\hline
\end{tabular}

was observed in all the parameters. Maximum moisture content $(76.62 \%)$ was found in cultivar AH006 while minimum dry mater $(23.38 \%)$ was found in AH006. The total soluble solids (TSS) and pH were ranged from 18.80 to $27.30 \%$ and 4.53 to $4.75 \%$ respectively. Total sugar content was found the highest (17.01\%) in AH001 whereas the lowest (11.84\%) found in AH003. Maximum reducing sugar content (4.59\%) and maximum non reducing sugar content (12.42\%) were found in AH001. The maximum vitamin $\mathrm{C}$ content was found $(31.55 \mathrm{mg} / 100 \mathrm{~g})$ in cultivar AH010 while that of min- imum $(17.82 \mathrm{mg} / 100 \mathrm{~g})$ was found in AH008. Highest acidity $(0.075 \%$ as citric acid) was observed in AH009 followed by $\mathrm{AH} 008(0.068 \%$ as citric acid $)$ where as AH005 had the lowest acidity $(0.037 \%$ as citric acid). Ash content of different jackfruit cultivars were ranged from 0.403 to $1.276 \%$. These results were found similar to earlier findings of Bhatia et.al. (1995) in jackfruits (Reddy et.al., 2004; Silvaraj and Pal, 1989; Chadha and Pareek, 1993 and Jagadish et.al., 1989).

Consumer's acceptability of jackfruit depends mainly on appearance (colour), flavor and taste. Hence, organoleptic

Table III. Nutritional food value of ten jackfruit cultivars in Rajshahi region

\begin{tabular}{|c|c|c|c|c|c|c|c|c|c|c|c|}
\hline $\begin{array}{l}\text { SL. } \\
\text { No. }\end{array}$ & Accessions & $\begin{array}{c}\text { Moisture } \\
\%\end{array}$ & $\begin{array}{c}\text { Dry } \\
\text { matter } \\
\%\end{array}$ & $\begin{array}{c}\text { Total } \\
\text { Soluble } \\
\text { Solids }(\%)\end{array}$ & $\mathrm{pH}$ & $\begin{array}{c}\text { Total } \\
\text { Sugar \% }\end{array}$ & $\begin{array}{c}\text { Reducing } \\
\text { Sugar \% }\end{array}$ & $\begin{array}{c}\text { None } \\
\text { Reducing } \\
\text { Sugar \% }\end{array}$ & $\begin{array}{c}\text { Vitamin } \\
\mathrm{C} \mathrm{mg} / \\
\text { 100gn }\end{array}$ & $\begin{array}{c}\text { Acidity } \% \\
\text { As Citric } \\
\text { Acid }\end{array}$ & Ash \% \\
\hline 1 & 2 & 3 & 4 & 5 & 6 & 7 & 8 & 9 & 10 & 11 & 12 \\
\hline 01 & АH001 & 63.39 & 36.61 & 24.5 & 4.55 & 17.01 & 4.59 & 12.42 & 20.35 & 0.055 & 1.119 \\
\hline 02 & АH002 & 74.40 & 25.39 & 21.1 & 4.65 & 13.29 & 3.58 & 09.71 & 28.00 & 0.056 & 0.928 \\
\hline 03 & АH003 & 73.63 & 26.37 & 18.8 & 4.55 & 11.84 & 3.43 & 08.41 & 28.30 & 0.053 & 0.859 \\
\hline 04 & AH004 & 70.74 & 29.26 & 22.0 & 4.45 & 13.64 & 3.81 & 09.83 & 23.54 & 0.058 & 1.203 \\
\hline 05 & AH005 & 76.14 & 23.86 & 22.1 & 4.53 & 13.70 & 3.56 & 10.14 & 19.92 & 0.037 & 0.806 \\
\hline 06 & AH006 & 76.62 & 23.38 & 19.6 & 4.70 & 12.35 & 3.45 & 08.90 & 22.23 & 0.046 & 0.103 \\
\hline 07 & АH007 & 67.82 & 32.18 & 25.3 & 4.47 & 16.74 & 4.35 & 12.39 & 22.70 & 0.063 & 1.076 \\
\hline 08 & АH008 & 68.67 & 31.33 & 24.2 & 4.45 & 16.12 & 4.19 & 11.93 & 17.82 & 0.068 & 1.932 \\
\hline 09 & АН009 & 62.39 & 38.60 & 22.1 & 4.75 & 13.70 & 3.67 & 10.03 & 28.95 & 0.075 & 1.516 \\
\hline \multirow[t]{3}{*}{10} & AH010 & 67.98 & 32.02 & 20.5 & 4.63 & 12.92 & 3.74 & 09.18 & 31.55 & 0.045 & 1.976 \\
\hline & LSD $5 \%$ & 0.0210 & 0.0133 & 0.0797 & 0.0132 & 0.0162 & 0.0126 & 0.0129 & 0.0030 & 0.00054 & 0.00079 \\
\hline & LSD $1 \%$ & 0.0288 & 0.0181 & 0.1090 & 0.0182 & 0.0222 & 0.0173 & 0.0178 & 0.0041 & 0.00074 & 0.00109 \\
\hline
\end{tabular}


Table IV. The grading of ripen jackfruit as judged by the panel of seven judges based of general qualities of jackfruits.

\begin{tabular}{|c|c|c|c|c|c|c|c|c|c|c|c|c|}
\hline \multirow{2}{*}{$\begin{array}{l}\text { SL } \\
\text { No }\end{array}$} & \multirow{2}{*}{ Accessions } & \multirow{2}{*}{$\begin{array}{l}\text { Physical } \\
\text { characters }\end{array}$} & \multicolumn{7}{|c|}{ Marking by individual judges (\%) } & \multirow[t]{2}{*}{ Total } & \multirow{2}{*}{$\begin{array}{l}\text { Mean } \\
(\%)\end{array}$} & \multirow{2}{*}{$\begin{array}{l}\text { Order of } \\
\text { rating }\end{array}$} \\
\hline & & & 1 & 2 & 3 & 4 & 5 & 6 & 7 & & & \\
\hline \multirow[t]{3}{*}{01} & AH001 & Colour & 70 & 65 & 68 & 75 & 72 & 71 & 69 & 490 & 70.0 & Good \\
\hline & & Flavour & 63 & 58 & 57 & 67 & 53 & 59 & 64 & 521 & 60.1 & Fair \\
\hline & & Taste & 81 & 83 & 85 & 84 & 82 & 80 & 82 & 577 & 82.4 & Excellent \\
\hline \multirow[t]{3}{*}{02} & AH002 & Colour & 60 & 52 & 57 & 49 & 50 & 52 & 48 & 368 & 52.6 & Fair \\
\hline & & Flavour & 45 & 43 & 41 & 50 & 53 & 51 & 49 & 332 & 47.4 & Fair \\
\hline & & Taste & 63 & 61 & 58 & 45 & 61 & 56 & 45 & 389 & 55.6 & Fair \\
\hline \multirow[t]{3}{*}{03} & AH003 & Colour & 73 & 78 & 69 & 73 & 75 & 71 & 76 & 515 & 73.6 & Good \\
\hline & & Flavour & 93 & 74 & 88 & 71 & 74 & 98 & 96 & 614 & 87.7 & Excellent \\
\hline & & Taste & 90 & 93 & 89 & 94 & 96 & 84 & 87 & 633 & 90.4 & Excellent \\
\hline \multirow[t]{3}{*}{04} & AH004 & Colour & 92 & 90 & 88 & 87 & 93 & 94 & 87 & 631 & 90.1 & Excellent \\
\hline & & Flavour & 75 & 82 & 80 & 85 & 78 & 76 & 84 & 560 & 80.0 & Excellent \\
\hline & & Taste & 78 & 88 & 78 & 86 & 88 & 86 & 83 & 587 & 83.9 & Excellent \\
\hline \multirow[t]{3}{*}{05} & AH005 & Colour & 75 & 72 & 78 & 63 & 86 & 69 & 77 & 520 & 74.3 & Good \\
\hline & & Flavour & 72 & 83 & 70 & 75 & 78 & 80 & 81 & 539 & 77.0 & Good \\
\hline & & Taste & 90 & 86 & 95 & 79 & 88 & 87 & 82 & 607 & 86.7 & Excellent \\
\hline \multirow[t]{3}{*}{06} & AH006 & Colour & 67 & 77 & 65 & 72 & 78 & 71 & 62 & 492 & 70.3 & Good \\
\hline & & Flavour & 60 & 57 & 54 & 63 & 65 & 60 & 59 & 418 & 59.7 & Fair \\
\hline & & Taste & 73 & 68 & 74 & 77 & 69 & 65 & 72 & 498 & 71.1 & Good \\
\hline \multirow[t]{3}{*}{07} & АH007 & Colour & 65 & 71 & 60 & 74 & 66 & 75 & 68 & 479 & 68.4 & Fair \\
\hline & & Flavour & 63 & 60 & 68 & 72 & 65 & 76 & 70 & 474 & 67.7 & Fair \\
\hline & & Taste & 70 & 73 & 61 & 66 & 74 & 70 & 62 & 476 & 68.0 & Fair \\
\hline \multirow[t]{3}{*}{08} & АH008 & Colour & 72 & 78 & 73 & 80 & 84 & 70 & 74 & 531 & 75.9 & Good \\
\hline & & Flavour & 66 & 72 & 65 & 63 & 68 & 81 & 62 & 477 & 68.1 & Fair \\
\hline & & Taste & 74 & 73 & 79 & 82 & 85 & 80 & 76 & 549 & 78.4 & Good \\
\hline \multirow[t]{3}{*}{09} & AH009 & Colour & 71 & 76 & 72 & 85 & 80 & 75 & 71 & 530 & 75.7 & Good \\
\hline & & Flavour & 68 & 62 & 60 & 65 & 59 & 63 & 54 & 436 & 61.6 & Fair \\
\hline & & Taste & 75 & 72 & 76 & 82 & 86 & 75 & 84 & 550 & 78.6 & Good \\
\hline \multirow[t]{3}{*}{10} & AH010 & Colour & 82 & 76 & 72 & 80 & 84 & 82 & 79 & 555 & 74.3 & Good \\
\hline & & Flavour & 78 & 72 & 68 & 73 & 78 & 82 & 81 & 532 & 76.0 & Good \\
\hline & & Taste & 80 & 85 & 81 & 78 & 85 & 82 & 80 & 571 & 81.6 & Excellent \\
\hline
\end{tabular}

testes were done on pulp (bulb) colour, flavour and taste of these fruits by a panel of seven judges. The results of the preferential comments from the panel members were summarized and converted into acceptability scores and also order of rating (Table IV). In this study, the cultivar AH004 made the highest score in the total acceptability and ranked as excellent followed by the cultivar of AH001, AH003, AH005 and AH010. (Shamsudin et.al., 2009; Reddy et.al., 2004; Rahman et al., 1994).

\section{Conclusion}

The results show that there are significant variations in the morphological fruit characters and nutritional food values of jackfruit such as total soluble solid, $\mathrm{pH}$, titrable acidity, vitamin C, sugar content, moisture content, pulp colour, flovour and taste. The study provides important information to the processing industry to produce better quality of commercial and thus can open product a potential market for commercial cultivation of jackfruit.

\section{Acknowledgements}

The authors are grateful to the Director, BCSIR Laboratories. Rajshahi for providing Laboratory facilities to carry out the research work. The authors are thankful to Mr. Debasis Talukder, Principal Scientific Officer, BCSIR Labroatories, Rajshahi for his heartiest co-operation to analyse the data and valuable suggestions. Thanks are also 
due to Mr. Md. Idris Ali, Tech. and Mr. Md. Monjurul Islam, Lab. Attendent for their co-operation and help throughout the research work.

\section{References}

Alam MA, Islam MS, Uddin MZ, Hossain MM and Bashir MM (2011), Fruit characteristics of ten jackfruit genotypes grown in Chapai Nawabgonj condition. J. Bangladesh Soc. Agric. Sci. Technol. 8(1\&2): 189 -192.

Bhatia BS, Siddapa GS and Lal G (1995), Composition and nutritive value of jackfruit. Indian J. Agric. Sci. 25: 303-306.

Biswas SK, Setty GR and Narasimham P (2001), Recent development in the processesing of jackfruit (Artocarpusheterophyllus Lam.) J. Bio-sci. 9: 66 -73.

Bose TK and Mitra SK (1990), Fruits: Tropical and Subtropical, Naya Prokash, 206 Bidhan Sarani, Calcatta 700 006, India, pp. 638-649.

Chadha KL and Pareek OP (1993), Advance in Horticulture. Malhotra Publishing House, A-383 Mayapuri Industrial Area, Phase-1, New Delhi, India, 4: 1715.

Dubois M, Gilles KA, Hamittion JK Rebers PA and Smith F (1956), A colorimetric method for determination of sugar. Anal. Chem. 28 (3): 360-366.

Gyorgy P and Pearson W N (1967), The Vitamins. Second Edition, Academic Pres, New York, U S A. p. 32.

Jagadesh SL, Reddy BS, Swamy GSK, Gorbal K, Hegde L and Raghavan GSV (2007), Chemical composition of jackfruit (Artocarpus heterophysllus Lam) selection of western ghats of India. Food Chemistry. 102 (I): 361-365.

Jayaraman J (1981), Laboratory Manual in Biochemistry. New age International Lit, New Delhi. pp. 180.

Karmas E (1990), Techniques for measurement of moisture content of foods. Food Technology. 34: 52.

Khanom SAA, Rokshana F, Khaleque A and Rahman MA (1994), Studies on the utilization of jackfruit (Autocarpus heterophyllus Lam.) in food products. Bangladesh J. Nutrition, 7(2): 5-9.

Miller GL (1959), Use of dinitrosalicylic acid reagent for determination of reducing sugar. Anal. Chem. 31 (3): 426-428.

Mohadevan A and Sridhar R (1982), Methods in Physiological Plant Pathology. Sivakami Publications, Indira Nagar, Madras 600 020, India. pp. 171.

Rahman AKMM, Enamal H, Mian AJ and Chesson A (1995), Microscopic and chemical changes occurring during the ripening of two forms of jackfruit (Artocarpus heterophyllus Lam.). Food Chemistry. 52: 405-410.

Rahman MJ, Haque MA and Haque MS (1994), Physicochemical characteristics of different types jackfruit during storage. Bangladesh Hort. 22 (1\&2): 75-83.

Ranganna S (1986), Handbook of Analysis and Quality Control for Fruit \& Vegetable Products. Tata Mc GrawHill Publishing Company Ltd. New Delhi. pp.1101.

Rahman MJ, Khatun MM, Uddin ASMM and Saha MG (2010), Fruit characteristics of ten jackfruit germplasm at Joydebpur. J. Bangladesh Soc. Agric Technol. 7 (1\&2): 87-92.

Rahman MJ, Khatun MM, Uddin ASMM and Saha MG (2010), Fruit characteristics of ten jackfruit germplasm at Joydebpur. J. Bangladesh Soc. Agric Technol. 7 (1\&2): 87-92.

Reddy BMC, Patil P, Kumer SS and Gavindaraju LR (2004), Studies on physico-chemical characteristics of jackfruit clones of soutn karnataka. Karntaka J. Agric. Sci. 17: 279-282.

Salunkhe DK and Kadam SS (1995), Handbook of Fruit Science and Technology, Production, Compossition, Storage and Processing. Marcel Dekker Inc, 270 Madison Avenue, New York, U S A. pp. 593-595.

Salunkhe DK and Kadam SS (1995), Handbook of Fruit Science and Technology. Production Composition. Storage and Processing. Published by Library of congress, 270 Madison Avenue, New York, U S A. pp. 123-169.

Salunkhe DK and Desai BB (1984), Postharvest Biotechnology of fruits. Vol. 1: CRC Pres, Boca Raton, Florida.

Selvaraj Y and Pal DK (1989), Biochemical changes during ripening of jackfruit (Artocarpus heterophyllus Lam). J. Food Sci. Technol. 26: 304-307.

Shamsuding R, Ling CS, Ling CN, Muda N and Hassan O (2009), Chemical composition of the jackfruit juice (Artocarpus heterophysllus Lam.) cultivar J33 during storage. J. App. Sci. 9: 3202-3204.

Sonwalkar MS (1951), A study of jackfruit (Artocarpus heterophyllus Lam.) seeds. Indian J. Hort, 8: 27-30.

Received: 18 October 2012; Revised: 03 October 2012; Accepted: 17 December 2013. 